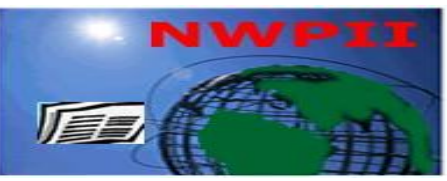

American Journal of Biomedical Sciences

ISSN: 1937-9080

nwpii.com/ajbms

\title{
Cyclomorphosis: The Adaptive Mechanism of Zooplankton in the Aquatic Ecosystem
}

\section{Joyce Osarogie ODIGIE ${ }^{* 1}$ and John Ovie OLOMUKORO ${ }^{2}$}

${ }^{1,2}$ Department of Animal and Environmental Biology, Faculty of Life Sciences, University of Benin, Benin City, Nigeria.

"Corresponding Author

Joyce Osarogie ODIGIE

Department of Animal and Environmental Biology,

Faculty of Life Sciences,

University of Benin, P.M.B. 1154,

Benin City,

Nigeria.

Email: joyce.odigie@lifesci.uniben.edu

Mobile: +2347036960280

Received: 29 November 2018; | Revised: 24 December 2018; | Accepted: 09 March 2019

\begin{abstract}
Cyclomorphosis is a temporal, cyclic or induced morphological change that occurs in the planktonic population, primarily as the outcome of abiotic or biotic factors in the environment. This phenomenon is noted in the dinoflagellates, rotifers, cladocerans and much strikingly in the copepods. In this study, search engines like the Google Scholar, National Science Library, PubMed and journal sites like the journal of freshwater biology were used for the literature search. Search terms include aquatic ecosystem, cyclomorphosis, rotifers, cladocerans, zooplankton, copepods and dinoflagellates. Detailed evidence-based literature was used to review the adaptive mechanisms of cyclomorphosis in an aquatic ecosystem. The research results suggest that the change that occurs in the lorica, size and number of outer ornamentation like spines and the shape of mastax in accordance to body shape is remarkable in zooplankton. The degree to cyclomorphosis which is developed within different populations of the same species is variable. Organisms can produce cyclomorphic variability in the tropical and subtropical regions as there is sufficient temperature difference among the seasons. The total body size may increase, decrease or remain the same throughout the cycle, depending on the species. Organisms produce exuberances that are not retained in all generations. However, little attention has been previously given to the non-exuberant side of cyclomorphosis. This review concludes that studies in cyclomorphosis are gradually going into extinction, as most of the works done were carried out in the past. Hence, the need for a revival of cyclomorphic research interest in this part of the world.
\end{abstract}

Keywords: Cladocerans, Copepods, Cyclomorphosis, Rotifers, Zooplankton 


\section{Introduction}

Cyclomorphosis is a temporal (seasonal or occasional), cyclic or induced morphological changes that occur in the planktonic population primarily as an outcome of abiotic or biotic factors in the environment. Though this concept began as a mere appreciation of variations in freshwater plankton, however, various researchers generated new and valuable findings on the causes and biological significance of this phenomenon ${ }^{[1]}$. Organisms with elongate spines or body parts, alternates annually, with forms lacking these exuberances. Cyclomorphosis has been reported for some planktonic algae, rotifers, and crustaceans ${ }^{[2]}$. The most bizarre forms are usually found during the warmer part of the year. Total body size may increase, decrease, or remain the same throughout the cycle, depending on the species ${ }^{[2]}$. One of the most unique phenomena in the biology of plankton is the occurrence of seasonal changes (cyclomorphosis), some of which are so striking that the summer and winter forms of the same species could be wrongly identified as belonging to different species. While it is certain that not all plankton organisms manifest such seasonal changes, they do occur in a large number of planktons, both plant and animal or scattered through the whole taxonomic range of the plankton series ${ }^{[3]}$.

A previous study shows that the term cyclomorphosis was first used by Lauterborn in 1904 to describe the "seasonal polymorphism" of plankton. Seasonal changes in the morphology of plankton populations have since been documented in dinoflagellates, rotifers, copepods and cladocerans ${ }^{[4]}$.In some literature like ${ }^{[5,6 \& 7]}$, shows that the studies done in the laboratory of Brooks ${ }^{[8,9]}$ revealed that cyclomorphism in certain cladocera and rotifer populations included the production of different phenotypes by the same genotypes in a seasonally distinct Lake environment. Suggestions by ${ }^{[10,11 \& 7]}$, also advocate that genetic change is an important component of cyclomorphosis. Among several assumptions that were put forth to explain its ecological significance, most suggested that cyclomorphosis probably act as an adaptive strategy against potential predators (both vertebrates and invertebrates) or as a phenomenon involved in maintaining and stabilizing buoyancy of organisms in the water column ${ }^{[12]}$. In addition, some researchers highlighted the importance of abiotic factors like temperature, turbulence and light for morphological variability among plankton ${ }^{[13]}$. In this respite, the aim of this study is to review the existing literature that underscored cyclomorphosis as an adaptive mechanism of zooplankton in aquatic ecosystems.

\section{Biological significance of cyclomorphosis in aquatic ecosystems}

The most prominent biological significance of cyclomorphosis in the aquatic ecosystem is the adaptive mechanism of organisms in the water body. It entails the forms and shapes in which these organisms take in a bid to adapt to various harsh environmental conditions in other to survive in the aquatic ecosystem. Seasonal polymorphism in zooplankton i.e. cladocera, rotifer and minimal in copepod have been assumed to be a major adaptive significance to these organisms.

\subsection{The Rotifers}

Cyclomorphosis, or seasonal polymorphism, is a seasonal morphological variation in successive generations of small aquatic organisms. Cyclomorphosis is a phenomenon that is particularly conspicuous, but fairly common among the protozoa, the dinoflagellates and the rotifers. A particularly comprehensive treatment of the subject of cyclomorphosis among plankton is the detailed résumé of ${ }^{[2]}$. Although it is more difficult to study the genetic continuity of seasonal forms of the same species of rotifers than of the planktonic crustaceans, cyclomorphosis in several rotifers has been analyzed in some depth. Seasonal polymorphism is therefore defined by the marked change in shape of some part of an organism in relation to some standard dimension of its size.

The common change in growth form in some rotifers include the following:

A. Elongation in relation to body width in some species of Asplanchna- Mid-summer populations can be about five times long and wide, and changed from their nearly spherical morphology in late spring. These elongated forms are nearly always sterile, die back and do not appear until the next spring. 
B. Enlargement, with the formation of bodywall outgrowths or humps- In Asplanchna sieboldi, this seasonal change in growth appears to be caused by the tocopherol content of plant-derived food and most likely is an adaptive response to cope with larger-sized food in summer.

C. Reduction in size- At higher temperatures in summer, a disproportionate reduction in length of lorical spines is observed. This change is common among several species of Keratella. Its adaptive significance is unclear since the reduction in spine length increases sinking speed at higher summer temperatures and is compensated for size. The causal mechanisms for the reduction in spine length are unclear.

D. Production of lateral spines- The beststudied case of this type of cyclomorphosis is in Brachionus calyciflorus, in which the posterior spines elongate in the presence of its major predator, the large rotifer Asplanchna. B. calciflorus always has two pairs of anterior spines and one pair of posteromedian spines. A pair of posterolateral spines may or may not be present.

Also in rotifers, the extension of preexisting anterior and posteromedian spines and "de novo" induction of large posterolateral spines are caused by a substance released into the medium by the predatory Asplanchna ${ }^{[14,15]}$ (Figure 1). These form changes cannot be explained by temperature induction or by an allometric growth response in which the substance works indirectly on the spines by influencing body size. Changes in body size were found to be independent of posterolateral spine production. The substance was shown to affect the spine form only at the egg stage before cleavage. The substance released by Asplanchna is a relatively thermolabile proteinaceous compound of unknown composition (Figure 2). The shape and movements of long posterolateral spines in B.calyciflorus significantly decrease predation by Asplanchna. Adult A. girodi which captured about $25 \%$ of newly hatched, spineless Brachionus with which they made direct contact, were completely unable to capture the newly hatched, long-spined individuals. Adult A. sieboldi can capture nearly $100 \%$ of adult spineless B. calyciflorus contacted, but only about $78 \%$ of adult, long-spined forms. The capture rate drops to $<15 \%$ of the spined form by young A. sieboldi. The spines, however, provide no protection against predation by the copepod Mesocyclops ${ }^{[16]}$.

A number of analysis of natural populations substantiate the fact that the substance released by Asplanchna can induce posterolateral spine production in B. calyciflorus populations $[17,18]$. Posterolateral spine length was found to be unrelated to water temperature but varied both with the density of Asplanchna and the presence of threshold quantities of the Asplanchna-released substance. Additionally, the significance of predation upon rotifers varies depending on the species represented in the predator-prey interaction. For example, the predatory, copepod Mesocyclops feeds effectively on the rotifers Asplanchna and Polyarthra but not on the rotifer Keratella ${ }^{[19]}$. Keratella is usually released by Mesocyclops after it has been captured because the predator cannot remove the soft parts of the rotifer. Asplanchna regularly eats Keratella but cannot capture Polyarthra because of its effective escape behaviour. The abundance of Polyarthra and Keratella in natural communities can be greatly affected by interactions with Asplanchna and predatory copepods (Figures 1 and 2).

In a recent study by ${ }^{[22]}$, cyclomorphosis occurrences in the freshwater rotifers - Brachionus caudatus was assessed from May 2012 to October 2012 in Tighra Reservoir Gwalior. It was observed that in the month of May, the total length was $0.210 \mathrm{~mm}$ which decreased to $0.157 \mathrm{~mm}$ in October. Similarly, the length of lorica decreased from $0.150 \mathrm{~mm}$ to $0.120 \mathrm{~mm}$ and the width of lorica decreased from 0.135 to $0.105 \mathrm{~mm}$ respectively (Figure 3). They, however, asserted that in this species, the cyclomorphosis was prominently influenced by the change in physico-chemical parameters of water particularly due to a seasonal change in temperature. 

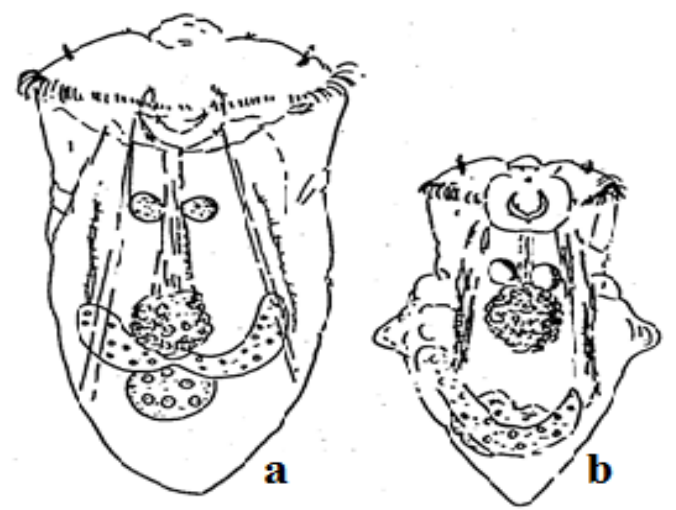

\section{Asplanchna-Brachionus interaction}
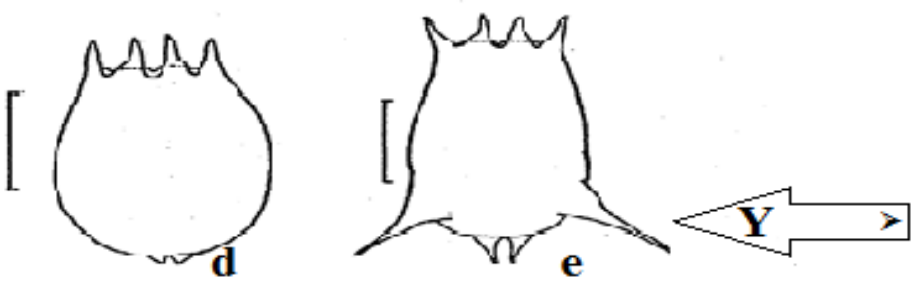

Development of spines in
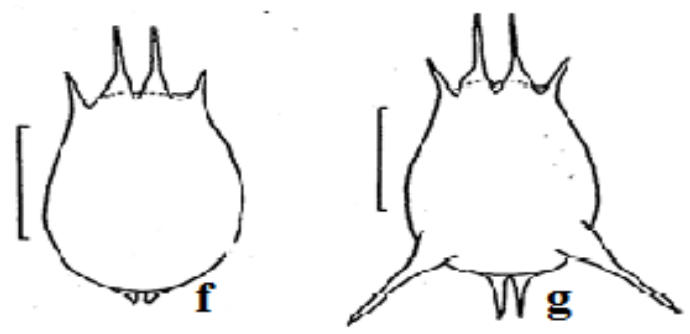

Brachionus in the presence of

Asplanchna. Living in the same

water has the same effect $=$

kairomone

Figure 1: Shows $X=$ Asplanchna sieboldi morphotypes (a). Campanulate (Bell-shaped), (b). Cruciform (humped shaped), (c). Sacate (sack-like shape). Note: they differ in ecology and physiology as well as in shape and size. $Y=$ Brachionus calyciflorus polymorphic forms or ecotypes (d) typica form (e) form anuraeiformis, (f) form Dorcas and ( $g$ ) form amphiceros. Scale lines $100 \mu \mathrm{m}$. Source: ${ }^{[16]}$.

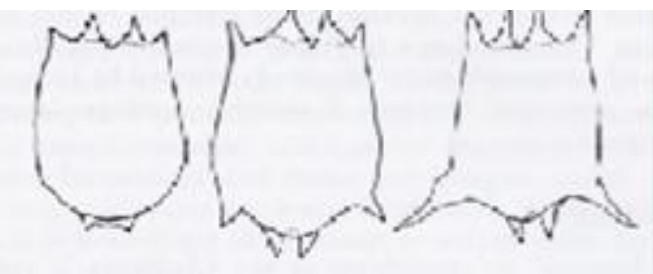

$\mathbf{A}$

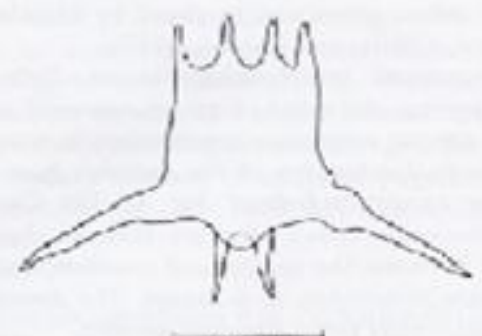

100

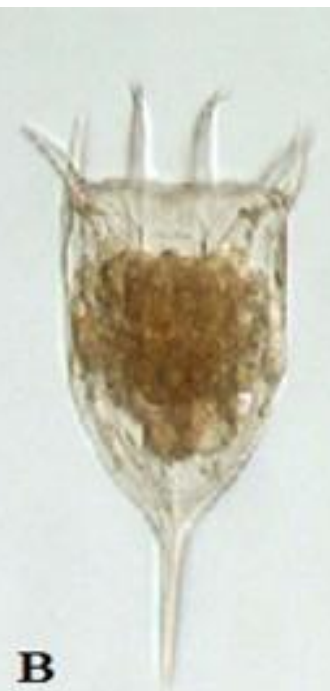

B

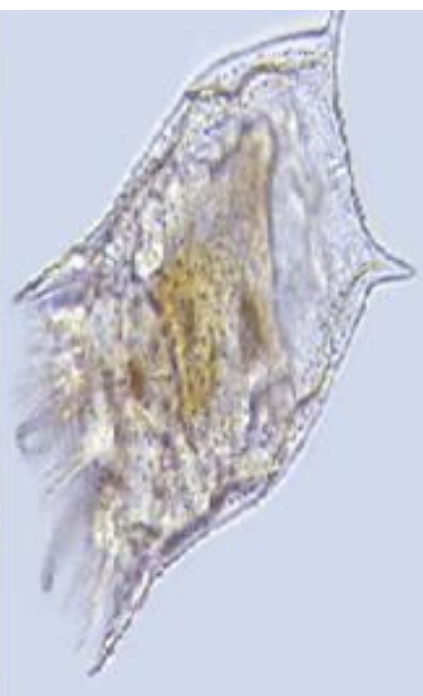

Figure 2: (A) Spine variations in a clone of the rotifer Brachionus calyciflorus induced by increasing concentrations of a proteinaceous substance produced by its predator Asplanchna. (B) Lorica divided into plaques, 6 anterior spines and 1 or 2 posterior foot absent- Keratella. The length of rotifer spines increase during summer months (cyclomorphosis), and they are generally thought of as anti-predator devices and projections that slow sinking. Source: ${ }^{[20,21]}$. 


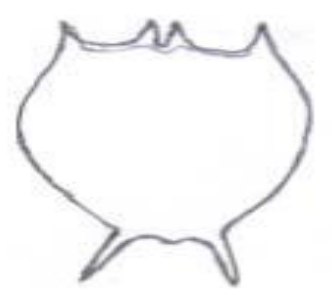

May

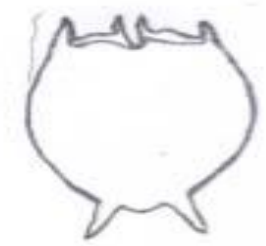

August

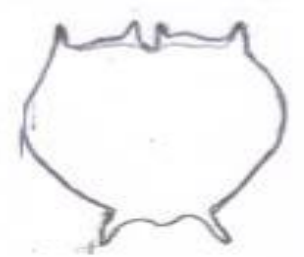

June

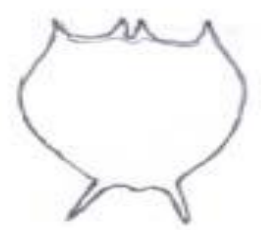

September

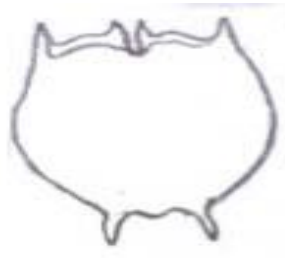

July

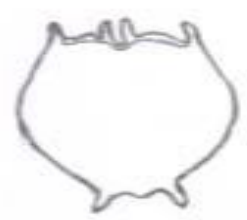

October

Figure 3: Camera Lucida images of Brachionus caudatus in different months. Source ${ }^{[22]}$

\subsection{Cladocera}

Seasonal polymorphism in the Cladocera is perhaps more conspicuous than in any other group. The subject has been studied extensively especially among the genus Daphnia and reviewed in detail by $[23,24 \& 2]$. When there is an increase in water temperatures, light and food in the spring, the most common seasonal pattern of variation among successive generations in a temperate Lake is a gradual extension of the anterior part of the head to form a crest or helmet. Carapace length, on the other hand, changes little or decreases only slightly between the spring and summer, and then increases again somewhat in autumn. The number of parthenogenetic eggs per individual generally decreases markedly in the strongly helmeted summer forms, although the number of instars increases with higher temperature.

However, the extent of head development and the change of head shape are extremely variable among species and within the same species under different environmental conditions. In subtropical and tropical waters, cyclomorphosis is weak or does not occur, except when there is a large temperature change between winter and summer ${ }^{[25,26]}$. An increase in the tail spine also is observed in some species during summer. Cyclomorphosis in the genera Bosmina, Ceriodaphnia, and Chydorus is much less distinct than in Daphnia and consists of slight reductions in length of the body and of the antennule in summer. In Bosmina, changes often occur by means of the formation of transparent dorsal humps, with no increase in length and reductions in antennule length and number of segments, in mucro (caudal spine) length and a number of sutures may also occur ${ }^{[4]}$.

Furthermore, the mechanisms causing cyclomorphosis in Cladocera have received many studies. It is clear that temperature is a primary stimulus affecting the height of the head helmet in Daphnia and that it is effective during the middle of embryogenesis. In a number of species, helmet extension does not occur at water temperature below $10-150^{\circ} \mathrm{C}$. Carapace length is maximal in winter and the ratio of head length to carapace length increase with increasing temperatures. Transfers of animal reared at one temperature to a lower or higher temperature result in a reduction or increase in head length in relation to that of the carapace in later instars. Food supply also affects the specific growth rate and has a relatively greater effect on the growth of the head ${ }^{[27]}$, but helmet length is more strongly correlated directly with water temperature than with food abundance ${ }^{[28]}$. Water turbulence also has been shown to be a significant factor in cladocerans cyclomorphosis ${ }^{[29-}$ ${ }^{321}$. Therefore, in turbulence cultures and in a naturally turbulent environment such as epilimnion of larger Lakes, helmet length relative to that of the carapace is increased significantly in the light in comparison to quiescent situations. Antennal beating rate also increases significantly in turbulent conditions, probably in order to maintain a vertical 
orientation to light. Helmet development is distinctly more conspicuous in species typically inhabiting epilimnentic turbulent strata [33]. Populations genetically capable of considerable phenotypic variation do not exhibit their extreme phenotype variation when they live in lower water strata in which growth is slower. Turbulence is virtually ineffective in cyclomorphic induction in the dark [7, 34]. Temperature and turbulence influence relative growth rates from the beginning of the second half of embryogenesis, whereby food becomes effective immediately after birth ${ }^{[35]}$. Daphnids Cladocerans that are warm, well fed, illuminated and exposed to turbulence produce the largest helmets. All factors are influential to some extent as long as the animals are capable of growth. The organic substances released by invertebrate (especially Chaoborus) and fish predators can also induce cyclomorphic growth in Daphnia more effectively than can changes in temperature, turbulence and oxygen ${ }^{[36-41]}$. Exposure to these chemicals cues is most effective at the juvenile growth stages. Although, a compensatory mechanism exists in Daphnid growth; the larger (longer) the helmet resulting from earlier influences, the slower it will grow relative to the body in later instars ${ }^{[23,35]}$.

However, certain body proportions are maintained regardless of previous environmental conditions. Since there is no single receptor mechanism for effective environmental factors; one or more hormones likely interact to regulate specific differential growth. In addition, morphological variability in Cladocerans has been ascribed only to phenotypic plasticity. It is important to note that some cyclomorphic species are in reality composed of many genetically differentiated species ${ }^{[4,23} \& 42-$ ${ }^{44]}$. A number of these species often occur in the same community and seasonal changes in their relative frequencies can cause polymorphic cycles that mimic true cyclomorphosis. Intraspecific genetic variation in head shape likely occurs as well in some species.

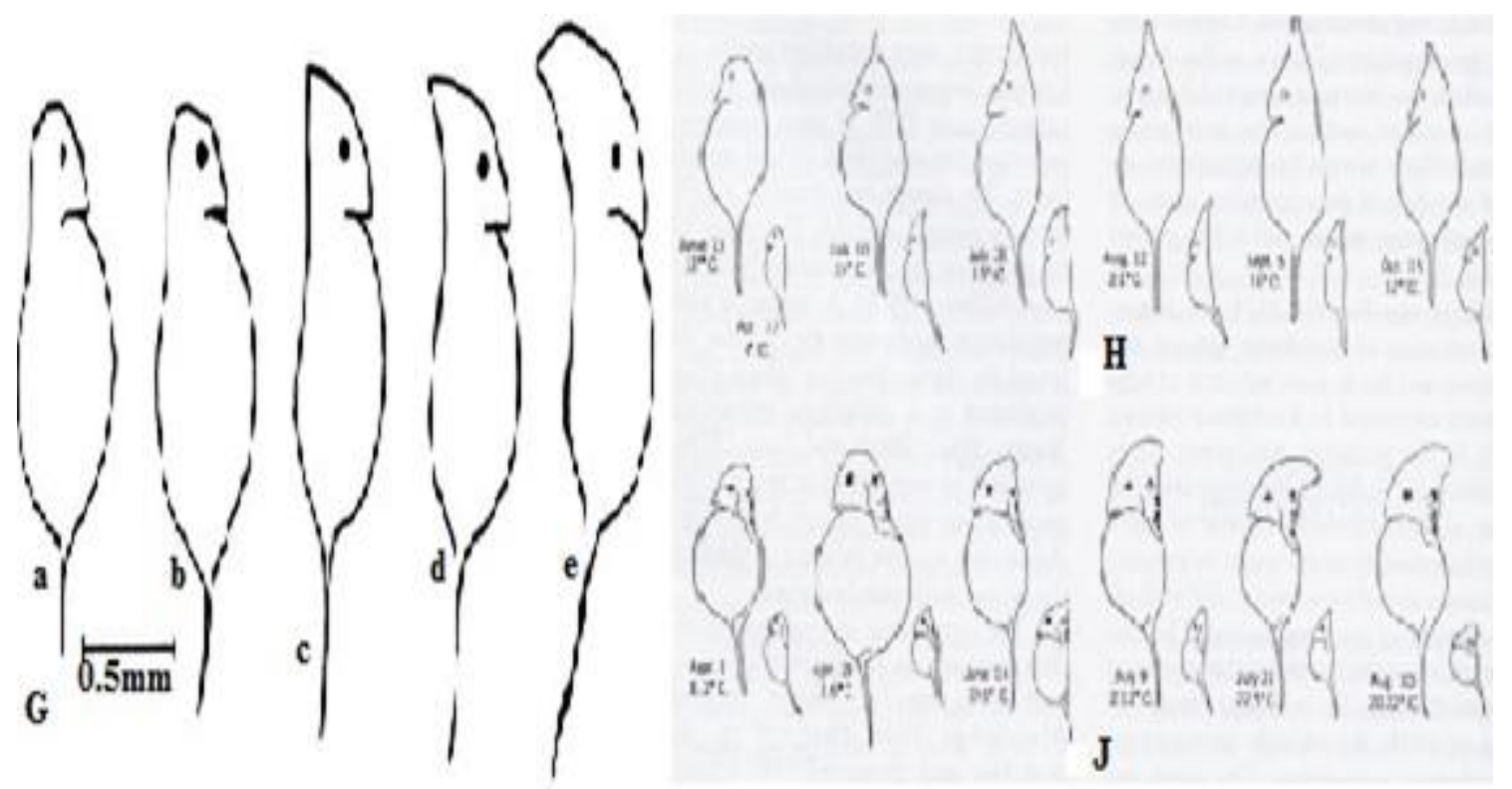

Figure 4: Shows $(\mathrm{G})$ seasonal variations in the helmet size, shape and shell spine length in $D$. retrocurva from Heney Lake. a,b- Typical round-headed spring forms, c- Helmeted form found in late spring, d, e- High helmeted forms found in summer. Cyclomorphosis in (H) Daphnia cucullata of Esrom So, Denmark and (J) Daphnia retrocurva of Bantam Lake, Connecticut. The small individuals at the right are first-instar juveniles drawn to the same scale as an adult. Source ${ }^{[2,9 \& 45]}$.

\subsection{Copepods}

Seasonal polymorphism among adult copepods is minor in comparison with what occurs among the parthenogenetic cladocera and rotifers. The most

conspicuous feature is a slight inverse relationship of body size to increasing temperature, so that, in few cases studied, animals of summer populations 
tend to be somewhat smaller than animals living in colder seas

\section{Conclusion and Recommendation(s)}

Cyclomorphosis is seen only in animals that are exposed to size-selective predation as a result of being smaller than or equal to the largest size preferred by invertebrates (about $1.5-2 \mathrm{~mm}$ for most pelagic predators). Although the adults of intermediate-sized species are strongly cyclomorphic, immature forms of the large Daphnia similis, not the adults, show a development similar to cyclomorphosis (this is not true cyclomorphosis, since the neonates always have high helmets and the adults never do). However, the morphological change with development during a lifetime is similar to changes seen in smaller species during an animal cycle of several generations. Cyclomorphosis should therefore, be correlated with fluctuations in predator density, but not necessarily with any specific set of environmental parameters. In a small geographic area, the intensity of invertebrate predation will be similar in comparable proximate Lake that correlates with environmental conditions. Predation patterns of widely separated Lakes are less likely to be similar and less likely to be correlated with the same environmental factors. Hence, the confusion about the "cause" of cyclomorphosis. Apparently, the widely held but seldom stated hypothesis is that the production of exuberances costs energy that could otherwise be used to increase the growth rate or to produce more eggs. The energy contained in a high helmet and long tail spine in D. galeata mendotae is worth only about a seventh of a resting egg as shown by ${ }^{[46]}$. He also found that Daphnia with high helmets sank faster than non-helmeted Daphnia. This suggests that the helmet also costs the extra energy used to maintain position in the water column. However, such speculation is science fiction; therefore, the following recommendations are made:

1. Curiously little attention has been given previously to the non-exuberant side of cyclomorphosis, hence the need for researchers to look in that direction.
2. Further research is also needed to show why organisms produce exuberances that are not retained in all generations.

3. Studies or research in cyclomorphosis is gradually going into extinction, as most of the works done in this field were carried out in time past. Hence, the need for a revival of cyclomorphic research interest in this part of the world.

\section{References}

1 Daday, E. V. Beitragezurkenntniss der Plattensce Faune. Math NaturwBer Ung 1885; 3:179-184.

2 Hutchinson, G.E. A Treatise on Limnology: Introduction to Lake Biology and the Limnoplankton. John Wiley and Sons Inc, New York, 1967; 2: 1115.

3 Welch, P.S. Limnology. McGraw Hill, New York. 1952; 2:538.

4 Black, R.W. The nature and causes of cyclomorphosis in a species of the Bosmina longirostris complex. Ecol. 1980a; 61(5): 1122-1132. https://doi.org/10.2307/1936832.

5 Kerfoot, W.C. The divergence of adjacent populations. Ecol. 1975b; 56: 1298-1313. https://doi.org/10.2307/1934698

6 Gilbert, J.J. Asplanchna and ostero-lateral spine production in Brachionus calyciflorus. Arch. Hydrobiol. 1967; 64: 1-62.

7 Jacobs, J. Cyclomorphosis in Daphnia galaeta mendotae Birge: A case of environmentally controlled allometry. Arch. Hydrobiol. 1961; 68: 7-71.

8 Brooks JL. Turbulence as an Environmental Determinant of Relative Growth in Daphnia. Proc Natl Acad Sci U S A 1947; 33(5): 141148 [PMID: 16578260 PMCID: PMC1079010]

9 Brooks, J.L. Cyclomorphosis in Daphnia: I. An Analysis of D. retrocurva and D. galeata. Ecol. Monograph 1946; 16: 409-447. https://doi.org/10.2307/1961644

10 Kerfoot, W.C. Seasonal changes of Bosmina (Crustacea: Cladocera) in Frains Lake, Michigan: Laboratory observations of phenotypic changes induced by inorganic factors. Freshwat. Biol.1975a; 5: 227-243. https://doi.org/10.1111/j.13652427.1975.tb00136.x 
11 Hallbach, U.; Jacobs, J. Seasonal selection as a factor in rotifer cyclomorphosis. Naturwissenschaften $1971 ; \quad 58(6): 326$. [PMCID: 5564476]

12 Lindholm , M. Predator - Induced Cyclomorphosis of Daphnia laevis (Branchiopoda, Cladocera) in a Tropical Floodplain (Okavango Delta, Botswana). Crustaceana 2002; 75(6): 803-814. https://doi.org/10.1163/156854002760289773

13 Yurista, P.M. Cyclomorphosis in Daphnia lumholtzi induced by temperature. Freshwat. Biol. 2000; 43: 207-213. https://doi.org/10.1046/j.13652427.2000.00543.x

14 Gilbert J.J. Sex-specific cannibalism in the rotifer Asplanchna sieboldi. Science 1976; 194(4266): 730-732 [PMID: 982038]

15 Pourriot, R. Relations predateur (Asplanchna brightwelli) sur la morphologie de la proie (Branchionus bidentata). Ann. Hydrobiol. 1974; 5: 43-55.

16 Gilbert, C.R. Hybopsis storeriana (Kirtland). Silver chub. In: Lee, D.S., Gilbert, C.R., Hocutt, C.H., Jenkins, R.E. and McAllister, D.E. Atlas of North American freshwater fishes. North Carolina State Museum of Natural History, Raleigh. 1980b; 194.

17 Green, J.; Lan, O.B. Asplanchna substrate and posterolateral spine length variation of the rotifer Brachionus calyciflorus in a natural environment. Ecol. 1974; 48(6): 1027-1031.

18 Gilbert, J.J.; Waage, J.K. Asplanchna: Asplanchna-substance and posterolateral spine length variation of the rotifer Brachionus calyciflorus in a natural environment. Ecol. 1967; 48: 1027-1031. https://doi.org/10.2307/1934559

19 Gilbert JJ, Williamson CE. Predator-prey behavior and its effect on rotifer survival in associations of Mesocyclops edax, Asplanchna girodi, Polyarthra vulgaris, and Keratella cochlearis. Oecologia 1978; 37(1): 13-22 [PMID: 28309281 DOI: 10.1007/BF00349987]

20 Gilbert, J.J. Asplanchna and ostero-lateral spine production in Brachionus calyciflorus. Archiv. Hydrobiol. 1967; 64: 1-62.

21 Stemberger, R.S.; Gilbert, J.J. Body Size, Food Concentration, and Population Growth in
Planktonic Rotifers. Ecol. 1985; 66(4): 11511159. https://doi.org/10.2307/1939167

22 Ahad, N.; Rao, R.J. Cyclomorphosis of freshwater rotifers- A study of Brachionus caudatus. Int. J. Fisheries Aqua. Studies 2017; 5(2):430-433. http://www.fisheriesjournal.com

23 Jacobs, J. Cyclomorphosis in Daphnia, In: R.H. Psters and R. De Bernardi Daphnia Italiano Idrobiol. 1st (eds.), 1987; 45: 325-352.

24 Kerfoot, W.C. Perspectives on cyclomorphosis: Separation of phenotypes and genotypes. In Ibid, 1980a; 470-496.

25 Zagro, M.S.A. A preliminary investigation on the cyclomorphosis of Daphnia gessneri in a Brazilian reservoir. S. Paulo, Balm. Zool. Univ. 1976;147-160.

https://doi.org/10.11606/issn.25263358.bolzoo.1976.121575

26 Mitchel, B.D. Cyclomorphosis in Daphnia carinata king from two adjacent sewage lagoons in South Australia. Aus. J. Mar. freshwat. Res. 1978; 29: 265-576. https://doi.org/10.1071/MF9780565

27 Dodson , S.I. Cyclomorphosis in Daphnia galeata mendotae Birge and D. retrocurva Forbes as a predator-induced response. Freshwat. Biol. 1988; 19:109-114. https://doi.org/10.1111/j.13652427.1988.tb00332.x

28 Lampert, W.; Wolf, H. G. Cyclomorphosis in Daphnia cucullata: morphometric and population genetic analyses. J. Plankton Res. 1986; $\quad 8: \quad 289 \quad$ $\quad 303$. https://doi.org/10.1093/plankt/8.2.289

29 Havel, J.E.; Dodson, S.I. Environmental cues for cyclomorphosis in Daphnia retrocurva. Forbes. Freshwat. Biol. 1985; 15:469-478. https://doi.org/10.1111/j.13652427.1985.tb00217.x

30 Jacobs, J. Light and turbulence as codeterminants of relative growth rates in cyclomorphic Daphnia. Intern. Rev. Ges. Hydrobiol. $\quad$ 1962; 47:146-156. https://doi.org/10.1002/iroh.19620470109

31 Hrbacek, J. Circulation of water as a main factor influencing the development of helmets in Daphnia cucullata Sars. Hydrobiol. 1959; 13: 170-185. 
https://link.springer.com/article/10.1007/BF00 $\underline{046216}$

32 Brooks JL. Turbulence as an Environmental Determinant of Relative Growth in Daphnia. Proc Natl Acad Sci U S A 1947; 33(5): 141148 [PMID: 16578260 PMCID: PMC1079010]

33 Brooks, J.L. The relationship between the vertical distribution and seasonal variation of limnetic species of Daphnia. Verhandlungen Internationale Vereinigung fur theoretische und angewandte Limnologie 1964; 15: 684694.https://doi.org/10.1080/03680770.1962.11 895591

34 Hazelwood, D.H. Illumination and turbulence effects of relative growth in Daphnia. Limnol. Oceanograph. 1966; 11: 212-216. https://doi.org/10.4319/lo.1966.11.2.0212

35 Jacobs, J. Environmental control of cladoceran cyclomorphosis via target-specific growth factors in the animal. In: Evolution and Ecology of Zooplankton Communities, Ed. by Kerfoot, W.C. University Press, New England, Hanover, 1980; 429-437.

36 Tollrian , R. Fish-kairomone induced morphological changes in Daphnia lumholtzi (Sars). Arch. Hydrobiol. 1994; 130: 69-75. DOI: $10.1093 /$ plankt/12.6.1287

37 Hanazato, T. Induction of development of high helmets by a Chaoborus-released chemical in Daphnia galeata. Arch. Hydrobiol. 1991; 122: 167-175.

38 Chouhan, P.; Kanhere, R.R. Diversity of Zooplankton in Barwani Tank of West Nimar, MP, India. Res. J. Ani. Vet. Fish. Sci. 2013; 1(3):121-125.

http://www.isca.in/AVFS/Archive/v1/i3/2.ISC A-RJAVFS-2013-021.pdf

39 Tollrian, R. Predator-induced helmet formation in Daphnia cucullata (Sars). Arch. Hydrobiol. 1990;119:191-196.

https://www.cabdirect.org/cabdirect/abstract/1 $\underline{9940501675}$
40 Vourinen, I.; Ketola, M.; Walls, M. Defensive spine formation in Daphnia pulex Leydig and Induction by Chaoborus crystallinus. De Geer. Limnol. Oceanogr. 1989; 34: 245-248. https://doi.org/10.4319/lo.1989.34.1.0245

41 Grant, J.W.G.; Bayly, I.A.E. Predator induction of crests in morphs of the Daphnia carinata King Complex. Limnol. Oceanograph. 1981; 26:201-218.

https://doi.org/10.4319/lo.1981.26.2.0201

42 Kerfoot, W.C. Transparency, body size, and prey conspicuousness. In Ibid, 1980b; 609-617.

43 Lindholm, M . Predator - Induced Cyclomorphosis of Daphnia laevis (Branchiopoda, Cladocera) in a Tropical Floodplain (Okavango Delta, Botswana). Crustaceana 2002; 75: 803-814. DOI: $10.1163 / 156854002760289773$

44 Laforsch , C.; Tollrian, R. Inducible Defenses in Multipredator Environments: Cyclomorphosis in Daphnia cucullata. Ecol. 2004; $85, \quad 2302 \quad-\quad 2311$. https://doi.org/10.1890/03-0286

45 Toumi, H.; Bejaoui, M.; Boumaiza, M. Cyclomorphosis in Daphnia magna and Ceriodaphnia reticulate (Cladocera) from northern Tunisian groundwater: Influence of temperature and invertebrates? Crustaceana 2015; $\quad 88: 1139 \quad-\quad$ 1148. DOI: $\underline{10.1163 / 15685403-00003460}$

46 Chouhan, P.; Kanhere, R.R. Diversity of Zooplankton in Barwani Tank of West Nimar, MP, India, Res. J. Ani. Vet. Fish. Sci.2013; 1(3):121-125.

http://www.isca.in/AVFS/Archive/v1/i3/2.ISC A-RJAVFS-2013-021.pdf 